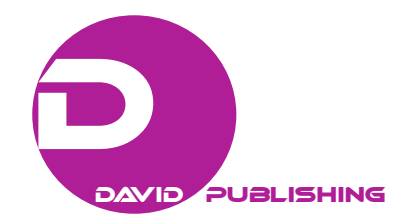

\title{
The Objectives and Basis of Public Administration Reform (PAR) Strategy
}

\author{
Slim Chtioui \\ University of Sfax, Tunisia
}

\begin{abstract}
Recent administrative studies show that the principals and basis of public administrative reforms (PARs), which are considered the guarantor of the achievement of the desired objectives in terms of the performance and effectiveness of the public service are offered to citizens. On this paper, special attention is given to the issues considering the rationalization of state administration organization and management, decentralization, the civil service and human resources management, high control mechanisms of public administration and protection of legality, access to information of public importance. The lack of legal culture, poor quality of legislation, hierarchic nature of decision-making, weak local budgets and administrative capacities could be considered as the main obstacles for the PAR strategy implementation.
\end{abstract}

Keywords: public administration reform (PAR), performance, rationalization, effectiveness

\section{Introduction}

In recent years, many countries have undertaken administrative reform as a crucial step towards strengthening their economy and better management of their social development. The state is still playing a key role in the change management of nations.

The United Nations programme in public administration and finance has continuously supported developing countries and countries in economic transition in their efforts to reform their public administration structures.

Public administration involves the development, implementation, and management of policies for the attainment of set goals and objectives that will be to the benefit of the general public. Since public administration involves taking decisions that affect the use of public resources, there is often the question of how to utilize public resources for maximum public good.

The growing interest in administrative reform in developing countries has several origins. Important among these are three: One relates to the concern for improved performance in public bureaucracy through modernization of methods, techniques, and procedures of work and more effective management of human resources. Another is the process of change required within the government sector to sustain efficient market-led economies in the emerging context of globalization. The third is the increasing concern for efficient and effective delivery of key public services through decentralization involving devolution and delegation of powers and authority to lower levels of administration by the modification of departmental functions, and the 
machinery of government for policy coordination.

While these three principal sources are the prime movers, administrative reform is characteristically focused on the capacity of government to make and implement public policy, the effectiveness of public programs, and strengthening of public institutions on a sustainable basis within the caveats of responsiveness, accountability and equity.

The establishment of competent, effective, efficient, accountable, service-oriented, and transparent public administration is the final objective, towards which the public administration reform process is headed, but mostly due to fulfilling the needs of the citizens and the business community.

Also, there is a universal agreement that administrative reform is a continuous process. Not all countries have the institutions and resources necessary to pursue such a systematic approach. Major constraints are the costs and practicability.

Public administration reform (PAR) strategy envisages a set of steps, which should lead to more effective, efficient, and improved management of institutions, human resources, and processes, resulting with more efficient creation of policies, improved functionality and organization, merit-based human resources management, more efficient and cost effective public services, as well as bigger responsibility, reporting, and transparency of institutions, servants, and managing structures.

The aim of this paper is to focus on the principles and foundations of public administration reforms and the strategies to be implemented to achieve the desired objectives of performance and citizen satisfaction.

In order to do so, strategic axes will be detailed in this work which may be considered as the key factors of success and the pillars of effective and efficient reform.

Achieving the objectives of administrative reforms makes it possible to positively impact all sectors, in particular, the realization of economic performance and the guarantee with a high rate of economic growth as well as the satisfaction of citizens who have become increasingly demanding regarding the quality of the services offered by the administration.

A first section of this work will be reserved to detail the principles that must be ensured for effective and efficient administrative reform. The second section will focus on the foundations that guaranteed a successful administrative reform for all aspects of the business lines before ending with a final section that will try to focus on the objectives to follow that constitute the transmission channels offering the possibility to reach the final objective of the reforms that revolve around the performance, effectiveness, and dissemination of the practices of good governance.

\section{Section 1: Principles of Public Administration Reform (PAR)}

The principles upon which the PAR strategy is based are the principles of "good governance" (Cohen, 2010).

\section{Legality}

Legality is of crucial importance for good governance. Public institutions act fully and exclusively in accordance with the laws, and decisions and rules are adopted in legal procedures and they are implemented impartially. With regard to the public administration reform, rules should precisely and clearly stipulate obligations for the authorities, and prescribe rules for adoption of decisions and mechanisms for their implementation. 


\section{Integrity}

In accordance with the legal provisions, the public administration must be an honest and confident partner for the citizens and businesses. Ethics, professional integrity, and honesty of administrative servants are of paramount importance for achievement of the above stated.

Conflict of interests should be an evident reason for exemption from the decision-making process. The fight against corruption is a mandatory condition for modernization of the public administration; therefore, efficient measures for prevention and fight against all types of corruption must be granted. The integrity of professional servants shall be fully expressed by rightful application of the principle of delegation of competences when deciding in administrative procedures.

\section{Inclusivity and Impartiality}

A mechanism on full inclusion of the citizens should be provided, starting from policy creation and its realization. The public administration has an equal treatment towards all subjects (businesses and citizens), i.e., it is completely impartial and objective in adopting decisions. Any kind of discrimination is strongly forbidden. The access to all services is guaranteed for everybody, especially for the most vulnerable citizens and citizens from underdeveloped regions (Sigma, 2010c).

\section{Openness and Transparency}

Decisions must be adopted, approved, and implemented throughout precise and clearly established rules and procedures. All public information must be made available. Information on adopted decisions, their implementation, and results must be made available to the public, in a way that each citizen could have access to them and could contribute to controlling activities made by authorities.

\section{Professionalism}

Professional competences and expertise of those who adopt decisions must be kept at the highest level, and at the same time, mechanism for continuous improvement of such qualities must be provided, especially by foreseeing mandatory continuous trainings. Administrative servants must be motivated for improvement of their performances and must develop and apply methods and procedures for improvement of their performance management skills.

\section{Service Orientation}

The activities, procedures, and decisions adopted by the public administration must meet the expectations and needs of the citizens and businesses. Information on procedures for providing public services, as well as on public administration activities, must be provided correctly and timely, and public services must be provided on an adequate manner and within a reasonable time. Further reduction of discretional powers is also a pre-condition for full implementation of the service orientation principle.

\section{Efficiency, Effectiveness, and Cost Efficiency}

The public administration creates policies and strategies, leads procedures, manages projects, and provides efficient and cost effective services for optimization of results for the society, citizens, and businesses.

Assessment of performances of administrative servants' and their management throughout measures for positive and negative achievements must contribute to a better efficiency and effectiveness. Control mechanisms should also provide estimation and improvement of performances. 


\section{Vision and Sustainability}

The administration must provide middle- and long-term optimization of use of resources and work efficiency. The needs of future generations are directly linked and dependent from ongoing policies. Decisions adopted today must be visionary and sustainable and cannot cause financial, economic, or social problems for future generations.

\section{Accountability}

The role and responsibilities for adoption of decisions must be clearly and precisely established for each institution, collective body, or any other public policy-maker. All decisions must be adequately and clearly justified. The discretionary powers in the decision-making process must be excluded where possible. Efficient and cost effective mechanisms for legal protection must be placed, also for preventing any type of illegality and violation of human rights.

\section{Section 2: Basis of Public Administration Reform (PAR)}

The public administration reform depends directly on the administrative tradition and culture of the country. The overall public administration reform process shall be based on:

- Establishment of overall horizontal coordination mechanism and control over the public administration reform process by the Ministry of Public Services on the county and the government as policy-makers in the field throughout established legal mechanisms for providing consequent implementation of determined objectives.

- All institutions in the strategy implementation and public administration reform process shall be guided by the principle of reporting before the citizens and other public services stakeholders, by establishing a system on continuous reporting and providing information for the public on new policies and results of their implementation (Eriksen, 2007).

- The central governmental institutions, foremost the government and the Ministry of Public Services, administration agency, Ministry of Finance shall fulfill key functions, which shall provide well organized, consistent and competent system on creation and enforcement of policies.

- Policy-planning shall be adjusted to the financial capacities of the government, enabling thus the government to meet the set-out objectives, with full involvement of the Ministry of Finance in this process.

- The decisions of the government shall be transparent and made available to the public, and the assembly shall perform supervision over the government's work, throughout continuous, ongoing information to the public on activities and decisions of the government, undertaking urgent measures for harmonization of legislation with authentic interpretations made by the assembly, including rulings.

- Additional mechanisms on inclusiveness of policy creation and legislation shall be developed, throughout mandatory public debates and forums, comparative experiences and expert opinions.

- Full implementation of the already established legal framework on professional and coherent public service, and consistent and effective practice on human resources management in the public service enabled by the institutional framework, throughout enforced implementation control.

- Public service professionalism provided throughout good management standards and practices on human resources management, regular and continuous trainings of public employees.

- Complete client oriented administration, with guarantees on the quality and availability of public services, 
throughout enhanced legal mechanisms on full implementation of laws, as well as advancement of processes by better use of information technology.

\section{Section 3: Objectives of the Public Administration Reform (PAR) Process}

The general objective of the PAR Strategy for each country will be achieved by reforming four priority areas:

- Strategic framework of public administration reform, policy development, and coordination;

- Public service and human resources management;

- Accountability, reporting, and integrity;

- Service delivery and ICT support to administration.

Achieving the objective of public administration reform shall be provided by increasing transparency, reporting, accountability, efficiency, and cost effectiveness in the public administration performance, in all aspects of its functioning, starting with procedures for creation and adoption of policies, until their full implementation and achievement of the rights and legal interests of the citizens.

\section{Strategic Framework of Public Administration Reform, Policy Development, and Coordination}

The process of public administration reform represents a continuous engagement in direction of providing professional, modern, service-oriented, transparent, and reporting administration, responsible before the citizens. In order to provide improvements in the legal system, rule-of-law, good governance, and proper functioning in all social spheres, key attention must be paid to improvement of the quality of laws and by-laws, their adequate implementation, the process of strategic planning, policy creation, and coordination (Fuller, 2010).

With regard to policy development, the role of official statistics is crucial. One of the challenges that policy-makers are facing is creation of strategies based on evidence and planning, i.e., to be issued based on relevant, timely, and exact statistical data in consultation with long term professional servants who know the working processes in the body they are working in.

At the time being, the statistical system is not user-oriented (user-friendly) sufficiently, and the dissemination of statistical data process is not fully in line with technological advancements and the level of use of ICT among data users.

Different data sources will provide improvement of the timing, better quality of indicators, more indicators, and at the same time, they will reduce the burden of reporting units.

- Implemented consistent and coherent process of policy coordination, strategic planning and coordination. This is possible by :

- Established efficient and functional system for PAR implementation: Established functional system for coordination of PAR, based on analysis, supported by all structures for policy coordination and strategic planning on all levels.

- Improved legislative environment: Coherent legal framework available, for qualitative and transparent legislation process at all stages and legal certainty for the citizens.

- Efficient structures and control mechanisms for support and coordination of policies and qualitative decision-making process: To ensure transparent system of quality control over horizontal and vertical processes and harmonization of the strategic program documentation, horizontal policies and financial resources for complex projects (Gercheva, Hooper \& Windisch-Graetz, 2009). 
- Improvement of quality and availability of statistical data for strengthening the process of policy-making and coordination of policies general explanation of the objective.

Continuous development of statistics and production and dissemination of statistical data in accordance with the ground principles of official statistics; efficient and on-time preparation and dissemination of qualitative statistical indicators that reflect the economic and social aspects and processes and provide safe source of user data for analysis of the conditions and adoption of decisions.

- Conducted census of population and household: The population census is crucial source of detailed statistical data on the social and economic condition of the population. Unlike other statistical activities, the census aims at providing trustworthy and comparable data, from the lowest level up to national and international level.

- Strengthened capacity for production and dissemination of statistical data in accordance: Improvement of statistical data quality and providing user oriented approach to data, which in general terms will provide improvement of the system transparency, policies, and achieved progress of the country.

\section{Public Service and Human Resources Management}

An integrated, efficient, and modernized work of the administration by using human resources management model based on competences is one of the strategic bases to success the public administration reform.

It is important to state that in the law, and additionally with the regulation for implementing recruitment procedures for administrative servants, a merit-based recruitment practice must be established, at all stages, without influences in the selection process of candidates, whilst the degradation and termination of recruitment criteria are quite explicit.

The same as recruitments, carrier promotion procedures for administrative servants are exclusively merit based and competitive, providing transparent criteria, whilst special conditions and procedures have been thoroughly regulated with by-laws. Non-selected candidates can object and file a complaint.

- Providing coherent institutional set-up of public administration, state bodies, and inspection services with sufficient autonomy of independent, regulatory, and supervision bodies (Parízek, 2010).

Re-organization, rationalization, and optimization of horizontal and vertical set-up of state bodies and inspection services, in accordance with the constitutional principle of division of powers, hierarchical subordination, by providing full independence of the independent regulatory and oversight bodies, establishment of strict legal criteria and control mechanisms on future creation of new bodies and re-examining the need (throughout quantitatively measured indexes) of existence of each of them in the same organizational set-up and in the same legal set-up.

- Coherent institutional set-up of state bodies and inspection services with sufficient autonomy of independent, regulatory, and oversight bodies.

A coherent institutional set-up of the state bodies and inspection services shall enable better work efficiency, full usage of available resources, better work coordination, better implementation of laws, overcoming thus the current overlapping of competences, strengthening the mechanisms for inspection and administrative supervision, with special emphasis on preventive control mechanisms. Despite this, the normative and status variety of the legal status and functioning of inspection services is of huge importance.

- Integrated and modern performance of the administration by applying the model of human resources management based on competencies (merit). 
- Full implementation of the law on public employees and the law on administrative servants.

Complete respect of the employment principle and carrier in the public service based on professional competences-merit (competence and professionalism) and the principle of equitable representation of all minority communities, in the recruitment procedure of the best candidates, throughout a fair and objective selection procedure, without external pressures, including promotion procedures, professional improvement, and evaluation of the administrative servants throughout their re-allocation from overcrowded institutions to institutions that need additional staff (Sigma, 2010b).

- Established human resources management model based upon competencies for public service providers in the public sector institutions.

Establishment of competences for public service providers (specific for each of the different public sector and public companies activities) is used in the selection and promotion procedures, professional improvement and evaluation, in order to improve the services for the citizens.

- Drafting analysis and adoption of law on public sector salaries.

Drafting an analysis on the possibility of adoption of law on public sector salaries, as well as its adoption, is of extreme importance for unified approach in the regulation of the position of the public sector employees. Attention must be paid on establishing system where the salary will be determined by the performance management of the employees and the quality of their work, and not by the financial and organizational set-up of the institutions where they are placed

- Enhanced system for professional education of administrative servants.

Re-defining of the position, structure, methods of financing and functioning of the academy; designing special trainings for separate categories of employees, formal regulation of the position of trainers.

\section{Accountability, Reporting, and Transparency}

Reporting and transparency in the public administration functioning are conditions for good governance and provision of quality public services.

The law on prevention of corruption stipulates that when using discretional powers, each elected or appointed official, is obliged to adopt decisions in good faith, taking into account all relevant facts and circumstances of the case, led by the principle of legality and equity.

- Improved concept of integrity throughout transparency and accountability orientated towards citizens and the business community.

- Established system of measures for prevention of corruption, conflict of interest, and ethics in the public sector.

Establishing a system for prevention of corruption and conflict of interests is essential for providing transparency, reporting, and accountability of the public administration. This system must encompass strengthened position and capacities of the state commission for prevention of corruption and other stakeholders in the process, enhanced control mechanisms as well as specific measures for implementation of the legal solutions, limitation of discretional powers, full implementation of the law on protection of whistleblowers, and a systematic problem-solving by using public assets in pre-election periods.

- Bigger transparency and reporting of institutions.

Increasing the transparency and reporting of institutions towards citizens shall be established throughout complete openness of the institutions to the citizens on all data of their interest which is not of confidential 
character. Establishing standards and data catalogues of public character, limitation of possibilities of discretional classification of information, and a bigger use of active transparency of institutions are essential for bigger transparency and reporting.

- To provide effective protection of the rights of the persons in practice before the administrative courts.

To improve the administrative justice by removing the legal and other obstacles which causing the ping-pong effect, to increase the efficiency of administrative disputes and introduce a system of continuous training of administrative judges and court servants.

\section{Providing Services and ICT Support to Administration}

In the last decade, significant attention is paid on reforms for improving delivery of public services. Global trends and digital transformation on public sector reforms and incremented use of information and communication technology (ICT) ${ }^{1}$ by citizens, transformed the public sector environment. This, as return, has quashed old limitations and resulted in bigger expectations of citizens, who are becoming more aware on their rights and have better access to public service information. Since competition in the private sector has increased the level of qualitative delivery of services to final users, citizens expect the same from the public sector as well. But the question is whether the public sector can be as agile as the private and whether sufficient technical resources could be allocated in the public sector (professional capacities and technology) for full implementation of commitments for e-government, all issues which deserve serious attention.

Rational investments in development of digital environment will enable cost efficient and quality of ICT project implementation, improvements of inter-institutional communication and communication between clients and administration (Parizec, 2010).

- Providing fast and simple public services.

- Increased quality and availability to public services.

The result refers to increased availability of the public services and increased quality of the public services. One part of the key activities are: creation and functioning of "single point of services" and conducting redesign of the public services throughout simplifying and digitalization, where the client will play a central role; introducing quality data standards and standards for providing services.

One part of the key activities in achieving this expected result are: designing integrated e-services portal with high level of sophistication; digitalization of public services registries; establishment of systems of electronic identification and authorization, etc.

- Rational investment in development of digital environment.

The result refers to organized and centralized coordination of the digital transformation for providing sustainability of the government investments in ICT.

One part of the key activities in achieving this expected result are: establishment of special body that will be in-charge on centralized level of the digital transformation process in the country, for improvement of the electronic communication channels among administration employees, introducing digital environment standards.

- Informed and satisfied clients.

${ }^{1}$ Information and communications technology (ICT) is an extensional term for information technology (IT) that stresses the role of unified communications and the integration of telecommunications (telephone lines and wireless signals) and computers, as well as necessary enterprise software, middleware, storage, and audiovisual systems, that enable users to access, store, transmit, and manipulate information. 
The result refers to regular and quality information service to the clients, who are able to evaluate the quality of public services and express their level of satisfaction.

One part of the key activities in achieving the expected results are: introducing a system of regular reporting of the administration and the public on changes in providing public services: introduction and implementation of web standards in the institutions, standards for people with disabilities included, continuous implementation of instruments for measurement of client satisfaction, etc.

\section{Conclusions}

We have attempted in this work to show that the principals and basis of public administrative reforms which must be ensured are the guarantor of the achievement of the desired objectives in terms of the performance and effectiveness of the public service offered to citizens.

In this paper, special attention is given to the issues considering the rationalization of state administration organization and management, decentralization, the civil service and human resources management, high education for public administration, control mechanisms of public administration and protection of legality, access to information of public importance, and personal data protection.

These reforms reinforce the principles of good governance and contribute to improving the quality of public services offered and satisfying the citizen in the services requested.

Finally, the lack of legal culture, unsatisfactory capacity of ministries responsible for the management of the PAR process, poor quality of legislation, hierarchic nature of decision-making, weak local budgets and administrative capacities and a lack of capacity to benefit from foreign support could be considered as the main obstacles for the PAR strategy implementation.

Developing countries must to invest more in the principals and basis of PAR strategy and resolve weaknesses mentioned in order to increase their level of development and ensure the desired performance in all sectors of activity.

\section{References}

Cohen, L. J. (2010). Administrative Development in "Low-Intensity” Democracies: Governance, Rule-of-Law and Corruption in the Western Balkans. Simons Papers in Security and Development No. 5/2010. Retrieved from https://pdfs.semanticscholar.org/822e/61899773808a5ff6396d23dca3a9af04b1f2.pdf?_ga=2.147316915.540497678.1576823 213-1996313637.1576823213

Eriksen, S. (2007). Institution Building in Central and Eastern Europe: Foreign Influences and Domestic Responses. Review of Central and East European Law, 32(3), 333-369.

Fuller, D. E. (2010). Public Administration Reform Theory in Transition Countries. Paper presented at the 18th NISPAcee Annual Conference, May 12-14, Warsaw, Poland.

Gercheva, D., Hooper, J., \& Windisch-Graetz, A. (2009). Towards More Effective State Institutions. Development and Transition, (12), 8-10.

Government of the Republic of Serbia (GRS). (2004). Action Plan for Serbian Public Administration Reform Implementation 2004-2008. Government of the Republic of Serbia.

Koprić, I. (2003). Local Government Development in Croatia: Problems and Value Mix. In H. Baldersheim, M. Illner, and H. Wollmann (Eds.), Local Democracy in Post-communist Europe (pp. 181-210). Opladen: Leske + Budrich.

Koprić, I. (2008). Managing Public Administration Reform in Croatia. Hrvatska Javna Uprava, 8(3), 551-565.

Koprić, I. (2010). Managing Performance in the Western Balkans Civil Service Structures. Retrieved from http://www.rcpar.org/mediaupload/publications/2011/20110314_Managing_Performance_WeBa_FINAL.pdf

Parízek, M. (2010). Performance Appraisal in the Western Balkans: Overview and Good Practices from a Capacity Development Perspective. UNDP. Retrieved from http://europeandcis.undp.org/ourwork/cd/show/4EBE992E-F203-1EE9-BCEF440D1A2E95FC 
Sigma. (2008). Serbia Public Service Assessment. Retrieved from http://www.sigmaweb.org Sigma. (2009). Serbia Administrative Legal Framework Assessment. Retrieved from http://www.sigmaweb.org Sigma. (2010a). Assessment Serbia 2010. Retrieved from http://www.sigmaweb.org Sigma. (2010b). Civil Service and Administrative Law Assessment. Retrieved from http://www.sigmaweb.org Sigma. (2010c). Democracy and Rule-of-Law Assessment. Retrieved from http://www.sigmaweb.org Sigma. (2010d). Policy-Making and Co-ordination Assessment. Retrieved from http://www.sigmaweb.org 